\title{
Der Mensch ist mehr als seine Krankheit
}

\section{Peter Weibel}

Dr. med., Geriater und Schriftsteller, Mitglied FMH

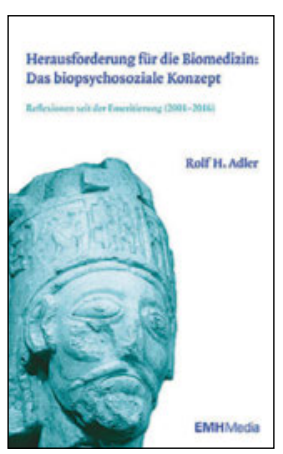

Rolf H. Adler

Herausforderung für die Biomedizin:

Das biopsychosoziale Konzept (2001-2016)

EMH Schweizerischer Ärzteverlag; 2017.

171 Seiten. 24.50 CHF.

ISBN 978-3-03754-107-4

Ein guter Arzt kann eine Krankheit behandeln, ein sehr guter Arzt den Menschen mit seiner Krankheit. Ich weiss nicht mehr, wem dieses Zitat zuzuordnen ist; es könnte auch von Rolf Adler stammen. Oder von George L. Engel oder Thure von Uexküll, den prägenden Vor-Pionieren der biopsychosozialen Medizin: Um den Menschen mit seiner Krankheit, nicht um die Krankheit ohne erkennbaren Menschen geht es in jedem Text dieser Sammlung. Reflexionen nach der Emeritierung als Chefarzt des Loryhauses am Berner Inselspital: Fünfundzwanzig Einzeltexte, verstreut über die Jahre 2001-2016, aufmüpfige Farbtupfer unter den fachmedizinischen Artikeln, die sonst die medizinischen Zeitschriften bevölkern. Sie beginnen mit der Theorie des biopsychosozialen Konzepts, der Kunst der Gesprächsführung (es ist eine Kunst, und sie ist lernbar), und springen dann mitten in den Praxisalltag hinein (er ist immer spektakulär, wenn er reflektiert wird).

Fünfundzwanzig Reflexionen, jede steht für sich und ist Teil eines Ganzen, jede erklärt ein Konzept oder bestätigt das Konzept, wenn sie ein Geschehen, eine Patientensituation überprüft und nach Antworten sucht. Wenn sie Antworten einfordert, wo einfache Fragen übersehen werden. Denn das Eigentliche liegt gerade in den banalen Fragen, die nicht gestellt werden. Soll der Arzt am Krankenbett stehen oder sich ans Bett setzen? Was tun, wenn der Patient Untersuchungen verlangt, die nicht weiterführen? Warum führt das gesamte Fachwissen nicht weiter, wenn der Arzt die subjektive Wirklichkeit des Patienten missachtet? Ist das Wesen Mensch ein offenes (katalogisierbares) oder geschlossenes (nur individuell erfahrbares) Modell? Wohin führt es, wenn die Sprache der medizinischen Apparaturen die Sprache zwischen Menschen verbannt?

Das Buch ist auch eine Kampfansage an das Diktat einer durchverwalteten, durchtechnisierten Medizin, die sich nachteilig auf das schwächste Glied in der Kette - den Patienten - auswirkt. Die Bedeutung der biopsychosozialen Medizin, die den Menschen nicht auf seine Krankheit reduziert, ist unwiderlegbar - aber sie hat im Zeitturbo von Technisierung und Ökonomisierung einen schweren Stand.

Der steinerne Blick auf dem Buchumschlag ist wissend und prüfend, nachdenklich und auch skeptisch; er ist nicht zufällig ausgewählt: Es ist die in Stein gemeisselte Empathie. Mit der reflektierten Sage vom guten norwegischen König Eysteinn dokumentiert der Autor, dass die Bedeutung der Empathie (Mit-Leiden) älter ist als ihre Einbettung in die Psychosomatik der Neuzeit, älter als ihre Anfechtung durch die mechanistische Medizin (in der ganz neuen Zeit): schon 750 Jahre vor Freud wusste Eysteinn um die Bedeutung des empathischen Gesprächs als Königsweg zum Heilen.

Der Essay über den guten König vermittelt eine Botschaft, die auch in anderen Aufsätzen anklingt. Der Autor findet Zusammenhänge, wo der kurze Blick nicht hinreicht, nur die Erfahrung, dass das Geheimnis des Menschseins an unvermuteten Orten erscheinen kann: In einer paradigmatischen Erzählung. In einer anekdotischen Episode. Oder auch in einem Lied von Mani Matter: Wenn der Arzt die Wirklichkeit des Patienten nicht würdigt, ergeht es ihm nicht anders als Matters Protagonisten Ir Ysebahn: Wer nur in die eigene Blickrichtung schaut, kann sich nicht vorstellen, dass die Wahrheit des Gegenübers eine andere ist, weil er in die Gegenrichtung schauen muss.

Wahrscheinlich ist die Zuordnung Reflexionen nach der Emeritierung nicht unwichtig. Denn die Zeit nach der Emeritierung hat Rolf Adler von vielem befreit. Seine Reflexionen sind grenzüberschreitend - oft narrativ, oft lustvoll, immer spannend, manchmal unerwartet spektakulär. Und dabei immer seiner Überzeugung, seinem Lebenswerk verpflichtet: Nicht nur die Krankheit zu würdigen, sondern den Menschen, der mit seiner Lebensgeschichte krank geworden ist. Die Botschaft ist unüberhörbar: Die Pforte muss für die biopsychosoziale Verstehensweise offen bleiben, weil es keine brauchbare Alternative gibt, auch nicht in dieser Zeit, in der die Medizin unbarmherzig ökonomisiert wird. 